\title{
NEGLIGENT USE OF PERSONAL PROTECTIVE EQUIPMENT BY CONSTRUCTION WORKERS IN SRI LANKA: ANALYSIS OF INDIVIDUAL MANIFESTATIONS
}

\author{
DASANDARA S.P.M. ${ }^{1} \&$ DISSANAYAKE D.M.P.P. ${ }^{2}$ \\ 1,2University of Moratuwa, Colombo, Sri Lanka \\ 1miyamidasandara@gmail.com, ${ }^{2}$ piumid@uom.lk
}

\begin{abstract}
The construction industry can be identified as one of the main sectors in Sri Lanka where the majority of occupational accidents happen. When considering the Small and Medium Enterprises (SME), occupational accidents have been significantly happened due to many reasons. Among those reasons, negligence of the use of PPE by construction workers has become prominent. Different factors can affect this situation. Among them, individual manifestations such as perceptions, beliefs, experiences and attitudes of the workers can make a significant impact. Hence, there is an emerging need to explore the reasons under these individual manifestations, which encourages the negligence use of PPE. This paper therefore aimed to analyse the individual manifestations to unveil the reasons behind the negligence of use of PPE by construction workers in Sri Lanka. A qualitative research approach was followed to achieve the aim of the study. Case studies were conducted using two SME construction projects. Fourteen semi structured interviews were conducted in both cases with managerial and worker level respondents. Collected data were analysed using code based content analysis. 'Considering PPE as a disturbance', 'lack of experiences of the workers', 'poor education level of the workers', 'inadequate knowledge and skills of the workers', 'poor income level', 'age of the workers', 'number of dependencies', 'poor health condition' and 'different lifestyles of the workers' were revealed through the empirical research findings as the key reasons under individual manifestations, which affect for the neglect usage of PPE by the workers. The knowledge generated through this study can be used in many ways by the industry practitioners to make safe working environment within the construction sites.
\end{abstract}

Keywords: Construction Industry, Negligence, Personal Protective Equipment (PPE), Small and Medium Enterprises (SMEs)

\section{Introduction}

The construction industry can be identified as a key sector, which highly affects for the economic development of any country (Ofori, 2015). Unfortunately, this sector has become one of the main sectors where occupational accidents highly happen day by day (Knibbs, 2009). As a developing country, SMEs in construction sector contribute more in socio economic development (Ofori, 2015). However, annual occurrence of occupational accidents is significantly high in this sector and this poor safety culture results different kinds of health hazards for the workers (Muema, 2017).

As same as to other countries, a similar situation can be observed in the Sri Lankan construction industry as well. Different reasons can affect for these occupational accidents in SME construction sites and among them, negligence of the workers to wear PPE is prominent because it increases the considerable amount of safety issues at the site (Ofori, 2015). PPE can be identified as equipment, which is used to minimise the workers' exposure to serious workplace hazards and injuries by ensuring their safety (Lombardi et al., 2009). Therefore, the primary concern should be given for the use of PPE in order to make a safe and healthy working environment at the sites. However, nowadays the majority of construction workers tend to neglect the use of PPE due to many reasons (Magoro, 2012). Among those reasons, workers' unsafe behaviours have made significant impact on the negligence of the use of PPE (Lombardi et al., 2009). These behaviours of the workers can differ from a worker to worker based on their individual perceptions towards safety, attitudes, beliefs, working experiences, and knowledge levels, which are generally named as 'Individual Manifestations' (Eskandari et al., 2017).

These manifestations need to be analysed in depth to determine the influence, which has been placed on the negligence of use of PPE by construction workers. Since a limited number of studies had been carried out about the negligence of use of PPE in Sri Lanka, it remains as a worthy researchable area. Accordingly, having identified the research gap, this paper intends to analyse the individual manifestations in depth to investigate the reasons behind the negligence of use of PPE by construction workers in Sri Lanka. Having identified the research gap, the research question can be formulated as 
"How individual manifestations could be influenced on negligent usage of PPE among construction workers in Sri Lanka”.

\section{Literature Review}

Sri Lankan construction industry can be identified as the most unsafe sector due to the occupational accidents, which happen constantly (De Silva and Wimalaratne, 2012). As further mentioned by them, this situation was highly apparent in SME sector as well. Many reasons can affect for these occupational accidents and among them negligence use of PPE by the construction workers has become a key reason, as disclosed by Ofori (2015). As a result, construction workers have become the main victims of these occupational accidents, nowadays (Ahamed et al., 2016).

As mentioned before, nowadays, construction workers highly tend to neglect the use of PPE due to many reasons (Magoro, 2012). As further stated by the author, mainly this situation happens due to unsafe behaviours of the workers. As stated in the previous section, these behaviours are influenced by individual manifestations. Individual manifestations can be defined as the human characteristics or human behaviours, which the workers' way of working and thinking can be affected (Eskandari et al., 2017). These individual manifestations include personal attitudes, perceptions, beliefs, knowledge or experiences of the workers, which can differentiate their behaviours (Lombardi et al., 2009). The Table 1 presents the reasons emerged from these individual manifestations, which affect for the negligence of use of PPE by the construction workers.

Table 1: Reasons affect for the negligent usage of PPE by the workers

\begin{tabular}{|c|c|c|c|c|c|c|c|c|}
\hline \multirow{2}{*}{$\begin{array}{c}\text { Reasons under the Individual } \\
\text { Manifestations }\end{array}$} & \multicolumn{8}{|c|}{ References } \\
\hline & $A$ & $\boldsymbol{B}$ & $C$ & $D$ & $\boldsymbol{E}$ & $\boldsymbol{F}$ & $\boldsymbol{G}$ & $\boldsymbol{I}$ \\
\hline 1. Poor personal attitudes of the worker & $\sqrt{ }$ & & $\sqrt{ }$ & & & & & $\sqrt{ }$ \\
\hline 2. Poor education of the workers & $\sqrt{ }$ & $\sqrt{ }$ & & & & & & \\
\hline $\begin{array}{l}\text { 3. Poor knowledge and skills of the } \\
\text { workers }\end{array}$ & $\sqrt{ }$ & $\sqrt{ }$ & $\sqrt{ }$ & & & $\sqrt{ }$ & & \\
\hline 4. Lack of past experiences of the worker & & $\sqrt{ }$ & & $\sqrt{ }$ & & & $\sqrt{ }$ & \\
\hline $\begin{array}{l}\text { 5. Age of the worker either encourage or } \\
\text { discourage the negligent usage of PPE }\end{array}$ & $\sqrt{ }$ & & & & $\sqrt{ }$ & & & \\
\hline 6. Poor perceptions of the workers & $\sqrt{ }$ & & & & $\sqrt{ }$ & & & \\
\hline \multicolumn{9}{|c|}{ 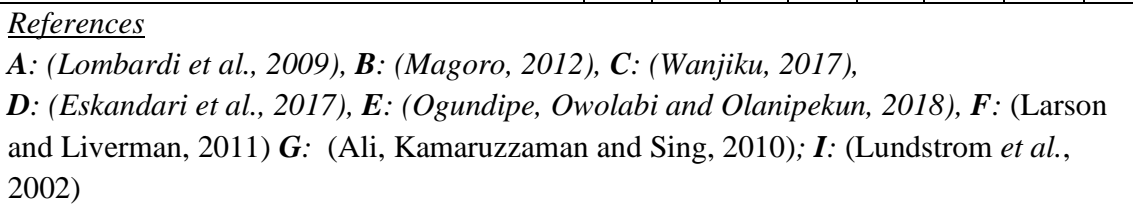 } \\
\hline
\end{tabular}

Ogundipe, Owolabi and Olanipekun (2018) stated that $81.1 \%$ of construction workers do not tend to use PPE due to poor personal attitudes because the majority of them perceive that PPE is inflictions for their works. According to Magoro (2012), knowledge of the workers affects the use of PPE as it refers to the basic understanding, which the workers have about the importance of the use of PPE. It was further emphasised in a recent study by Wanjiku (2017) that the level of education of the worker is one of the main manifestations, which affects the negligence of the use of PPE. Further, workers who have poor education have less understanding on the importance of wearing PPE in safeguarding their life. In addition, negligence can be encouraged due to the workers' poor attitudes. Attitudes describe their personal feelings based on their perception of the use of PPE. That means the decision of the workers to use PPE is based on their attitudes and perceptions of the risk, in the work they involve. Furthermore, workers' practices and experiences can be identified as another individual manifestation, which describe the way of demonstrating their knowledge and attitudes during their works (Magoro, 2012). The author emphasised that it can also adversely affects for the negligence of 
the use of PPE by the workers because working practices can be changed by the workers by considering their past experiences.

However, when it comes to Sri Lankan context, influence of these manifestations on negligent use of PPE by Sri Lankan construction workers have not been discussed in literature yet. Thus, in bridging this knowledge gap, this paper intends to analyse individual manifestations to investigate the reasons behind the negligence use of PPE. The next section discussed the research process adopted in bridging this knowledge gap.

\section{Research Methodology}

Having identified the need of analysing the individual manifestations to explore the reasons behind the negligence of use of PPE by Sri Lankan construction workers, the research question was developed as,

RQ: "How individual manifestations could be influenced on negligent usage of PPE among construction workers in Sri Lanka?"

Yin (2015) clearly stated that the selection of research strategy is based on three main criteria namely the type of the research problem, up to what extent the researcher has the ability of control over the behavioural events as well as whether the researcher focuses on contemporary events or not. Since, a contemporary phenomenon was followed through an in-depth investigation in this study (i.e. an investigation of individual manifestations, which affect for the negligence of use of PPE among construction workers) within its real-world setting, with a 'how' type of research question, case study research strategy can be identified as the most appropriate research strategy. Since this study aimed to explore reasons, emerged from individual manifestations behind the negligence of the use of PPE among construction workers, selecting multiple cases is the most suitable to gather data. Multiple cases are employed in order to repeat the same process with the purpose of deriving better results for the study (Yin, 2014). The number of cases was decided based on data saturation. Data saturation is reached when adequate and quality data are avail-able and further coding is no longer feasible to support the study (Fusch and Ness, 2015). Accordingly, two cases were selected to conduct the study. Fusch and Ness (2015) indicated that the unit of analysis can be identified as the main element in the case study design, where the use of PPE among construction workers has become the unit of analysis in this study. Also, cases were selected based on the SMEs since this study was limited to SMEs due to time constraints and limited accessibility (refer Table 2). Accordingly, cross case analysis was conducted by the researcher to draw conclusions at the end of the study.

Table 2: Profile of the Cases

\begin{tabular}{|l|l|l|}
\hline Description & Case A & Case B \\
\hline $\begin{array}{l}\text { 9 storied mixed } \\
\text { development project, with } \\
\text { an apartment and an office } \\
\text { building }\end{array}$ & $\begin{array}{l}\text { 5 storied building } \\
\text { construction project, which } \\
\text { is a proposed hostel } \\
\text { complex for a private } \\
\text { university }\end{array}$ \\
\hline $\begin{array}{l}\text { Contract Sum } \\
\text { Grading of the } \\
\text { Project }\end{array}$ & About 520 Million & About 400 Million \\
\hline $\begin{array}{l}\text { Number of } \\
\text { Employees }\end{array}$ & $\begin{array}{l}\text { Approximately } 40-50 \\
\text { employees }\end{array}$ & $\begin{array}{l}\text { C4 } 4 \\
\text { employees }\end{array}$ \\
\hline
\end{tabular}


Semi structured interviews were used in this study for the data collection because it facilitates the researcher to re-question from the interviewee for further clarifications regarding the research area as specified in the study by Fusch and Ness (2015). Accordingly, fourteen respondents were selected representing both managerial and worker level from both cases based on the nature of their works.

Table 3: Profile of the Respondents

\begin{tabular}{|l|l|l|l|l|}
\hline Project & Respondent & $\begin{array}{l}\text { Management/ } \\
\text { Worker }\end{array}$ & $\begin{array}{l}\text { Designation/ } \\
\text { Nature of Work }\end{array}$ & $\begin{array}{l}\text { Work } \\
\text { Experience }\end{array}$ \\
\hline CASE A & AM1 & Management & Site Engineer & 29 years \\
\cline { 2 - 5 } & AM2 & Management & Site safety officer & 30 years \\
\cline { 2 - 5 } & AE1 & Worker & Mason & 6 years \\
\cline { 2 - 5 } & AE2 & Worker & Carpenter & 9 years \\
\cline { 2 - 5 } & AE3 & Worker & Steel Fixer & 8 years \\
\cline { 2 - 5 } & AE4 & Worker & Welder & 8 years \\
\cline { 2 - 5 } & AE5 & Worker & Plumber & 7 years \\
\hline CASE B & BM1 & Management & Admin Officer & 8 years \\
\cline { 2 - 5 } & BM2 & Management & Project Manager & 12 years \\
\cline { 2 - 5 } & BE1 & Worker & Mason & 7 years \\
\cline { 2 - 5 } & BE2 & Worker & Bar bender & 10 years \\
\cline { 2 - 5 } & BE3 & Worker & Carpenter & 13 years \\
\cline { 2 - 5 } & BE4 & Worker & Rigger & 6 years \\
\cline { 2 - 5 } & BE5 & Worker & Plumber & 8 years \\
\hline
\end{tabular}

When the attention is paid to data analysis, content analysis can be identified as the most applicable, flexible as well as commonly used technique, which can be used to analyse textual data (Fusch and Ness, 2015). Hence, code based content analysis was used in order to carry out the data analysis. A code was given for each reason under the individual manifestations by providing a notation as described in below.

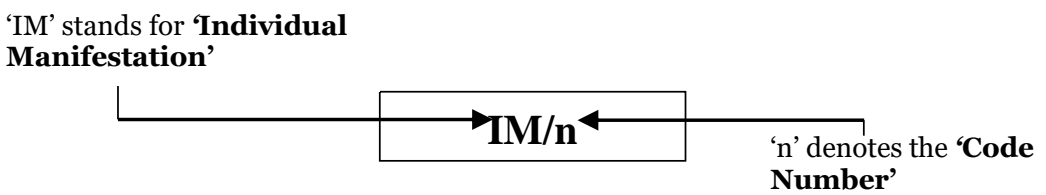

Figure 1: Coding Structure

\section{Research Findings and Analysis}

Detailed description of cross-case analysis of Case A and B is presented under the subsection of "Reasons under individual manifestations affect for negligence of use of PPE (Section 4.1)" as follows.

\subsection{REASONS UNDER INDIVIDUAL MANIFESTATIONS AFFECT FOR NEGLIGENCE OF USE OF PPE}

Poor personal attitudes and perceptions have been affecting intensively on the negligent use of PPE by Sri Lankan construction workers. It became apparent from the analysis of findings of both cases that "use of PPE has become a disturbance for the workers (IM/1)". It was because, use of PPE gives them an uncomfortable feeling while working, which delayed the work as mentioned by worker level interviewees. In addition, workers who work at high, face difficulties in handling tools due to wearing of some PPE (i.e. safety helmet) as PPE and other tools get tangled. Subsequently, they tend to ignore 
the use of PPE, not even realising the importance of them during the works. This poor attitude is sometimes encouraged by physical inconveniences they have to face due to the poor condition of the PPE. Sweating has become most common issue among these physical inconveniences, which the workers have to face. The situation is getting worst during hot climate periods, which can occur mostly throughout the year in Sri Lanka. This creates hard working environment for the workers, which leads to negligence of use of PPE by them during the works.

Also, workers' attitudes have been either encouraged or discouraged through their experience in the industry. It became clear through the case study findings that "workers who have less experience in the industry mostly tend to neglect the use of PPE (IM/2)". This fact is more common among young demographic. Being less experienced workers, they do not have in-depth understanding on the criticality of safety issues that they exposed to and the importance of use of PPE in mitigating such issues. Thus, they involuntarily tend to neglect the use of PPE during the works. The behaviour of the elderly works on this regard is the flip side of the experience coin. It is because, this finding cannot be corroborated among elderly workers, who have more experience in the field, as per AM2. He derived to a such conclusion through his 30 years' experience in the industry. Elderly workers are being experienced, they are aware of the potential risks that they expose while working. This became further evident through the behaviours of the elderly workers in Case A. Curiously, a contrasting outcome is observed in Case B. As described by BE1, some of the workers in Case B, who are having more experiences are not much concern about use of PPE due to the overconfidence, which they are being more experienced in the industry. Although this finding was substantiated with other workers who are not belong to above categories, they are also sometimes reluctant to use PPE due to physical inconveniences (refer Code IM/1).

Same as to the working experience in the industry, safety attitudes can be encouraged if the workers are having good educational background. It is because, the importance of wearing PPE for safeguarding their life can be easily communicated to them. However, this became a terrible task for managerial and supervisory level personnel due to the "poor education level of the workers (IM/3)". Accordingly, their poor educational level has been led to neglect use of PPE while working. However, such unsafe behaviours can be controlled up to some extent through proper trainings by top management. Unfortunately, such a commitment for the provision of trainings was not identified in both cases. Managerial level personnel justified the fact highlighting that providing training for such uneducated workforce is useless. Also, it incurred unnecessary cost since many of these workers are in temporary basis, as stated by AM1 and BM2. In addition to the poor educational background of workers, negligent use of PPE was also occurred due to the "inadequate knowledge and skills of the workers to use PPE (IM/4)". Workers should have the ability of using PPE in an accurate manner through their knowledge and skills. Unfortunately, such adequate knowledge and skills were not observed in both cases. Poor training facilities for the workers, which was discussed above may be a reason for this situation. As a result, many workers use PPE inaccurately and expose for different physical inconveniences most of the time. This might be one of the reasons for them to perceive use of PPE as a burden (refer Code IM/1).

As per the case study findings, "workers tend to accept any safety risk despite their income level, when the financial issues have become prominent (IM/5)". When the income level of workers is get into account in both cases, it was apparent that majority of these workers were at low income level. Therefore, they have to face many difficulties in their day to day life since they are suffered by many financial issues. This situation had created many negative impacts, which the workers encourage to earn more money at any risk and their safety has become a secondary concern. In a such context, workers ignore the use of PPE most of the time. In addition to the income level of the family, age of the worker can be identified as another demographic factor, which can make a significant impact on the use of PPE by the workers. It was witnessed through the analysis of case study findings that "young workers more reluctant to use PPE rather than old workers (IM/6)". Less experience of the young workers can mainly affect this situation (refer Code IM/2). However, the situation can be contrasted when they have dependents, despite the age. It was because, "workers tend to concern 
more about their safety when they have more dependents (IM/7)". This perception is more popular among workers who are married and have more dependents. Personal responsibilities in their life have influenced them to be careful while working.

More importantly, it was apparent through the analysis of findings of Case B that "poor health conditions of the workers have discouraged the use of PPE (IM/8)". As expressed by BE1, construction workers can be identified as hard workers who are working under hard working environment especially with warm climate in most of the time. As a result, different kinds of health issues can occur for them when wearing PPE for a long period of time in such a warm climate. As per the case study findings, 'headache' was identified as the most common health issue among workers. In such a context, workers involuntarily tend to remove PPE. Further, a unique finding, which was emerged only through case study findings is, different inherent lifestyles of the workers have encouraged the negligence of the use of PPE (IM/9). As mentioned by managerial level personnel of both cases, many workers are from different rural areas of the country. Majority of these workers seek temporary job opportunities for a short time period. Such kind of workers are most common in SME construction sites than larger construction sites. These workers are experiencing their inherent lifestyles, which are differentiated with their culture, religion as well as community. Since they have adhered to these inherent lifestyles, they dislike to change them. As a result, unsafe behaviours where the negligence of use of PPE has become very common are highly encouraged.

\section{Discussion}

The SME construction sector can be identified as one of the main sectors in Sri Lanka, where occupational accidents become more popular (Ofori, 2015). Many reasons can affect this situation and negligent use of PPE by the construction workers is prominent among them, as revealed by Knibbs (2009). Eskandari et al. (2017) identified in their study that workers' unsafe behaviours, which are differentiated by their individual manifestations make a significant impact on the negligence of use of PPE by them. Hence, this study endeavoured to analyse the individual manifestations to unveil the reasons behind the negligence of use of PPE by construction workers in Sri Lanka.

When mapping with literature findings, o6 main reasons under individual manifestations, which encourage the negligent usage of PPE by construction workers were captured. These reasons include 'poor personal attitudes of the workers', 'poor education of the workers', 'poor knowledge and skills of the workers', 'lack of past experiences of the workers', 'age of the workers' and 'poor perceptions of the workers' (refer Table 1). Although these findings were in general, they are almost similar to the Sri Lankan context according to the views of the many respondents (refer Section 4). Apart from those findings, 05 additional reasons were explored through the study. They can be listed as 'considering PPE as a disturbance (IM/1)', 'poor income level of the workers (IM/5)', 'number of dependencies of the workers (IM/7)', 'poor health condition of the workers (IM/8)' and 'different lifestyles of the workers (IM/9)'. These findings have not been discussed in the literature yet. Since majority of the workers in Sri Lankan construction sites have to face many physical inconveniences due to many reasons like poor condition of PPE and weather changes, they consider PPE as a disturbance for their works. This is in line with the findings by Ogundipe, Owolabi and Olanipekun (2018), which states that many workers perceive that PPE is infliction for their works. Further, as revealed through the case study findings, poor income level had created many negative impacts on the use of PPE by the workers because they tend to work at any risk due to the financial issues even though the physical inconveniences are occurred. Although Lombardi et al. (2009) insisted that the age of the workers can either encourage or discourage the use of PPE based on the experience they have, the situation can be differed when they have dependents, despite the age, as indicated by the respondents. Further, respondents revealed that construction workers have to work under the hard working environment most of the time due to the warm climate since Sri Lanka is a tropical country. This results poor health conditions of the workers, which discourage the use of PPE. Moreover, as per the views of the respondents, many workers are from different areas of the country with inherent living patterns, 
which they have already adhered. These different lifestyles can negatively impact on the use of PPE by them, which was highly evidenced in both cases.

On the whole, 11 reasons under workers' individual manifestations on negligent use of PPE by Sri Lankan construction workers were identified through the empirical findings. As per the case study findings, it was proven that these findings were highly relatable with the current situation of the industry. Thus, aforementioned reasons behind the negligence of use of PPE by the construction workers need to be get into account by the respective industry practitioners in order to make a safe working environment within construction sites in Sri Lanka.

\section{Conclusions}

When consider about the current situation of the occupational accidents in Sri Lankan SME construction sites, a higher rate of occurring accidents can be identified due to not wearing PPE by the workers. Therefore, reasons, which encourages the negligence of use of PPE by the workers should be properly identified to mitigate those occupational accidents in a significant manner. According to the empirical research findings, it was proven that behavioural changes of the workers as individuals, which relate with their individual manifestations mainly affect for the negligence of use of PPE by them. With regarding these behavioural changes, many causes were identified, which affect for this situation currently in SME construction sites. Accordingly, it is proven that many individual manifestations lead for different reasons, which encourage the negligent use of PPE by the workers. The knowledge generated through the study can be used by the industrial practitioners to make a safe working environment in Sri Lankan construction sites.

\section{References}

Ahamed, M. S. S. et al. (2016) 'Site safety of Sri Lankan building construction industry', pp. 1-12. Available at: http://www.civil.mrt.ac.lk/conference/ICSECM_2011/SEC-11-76.pdf.

Ali, A. S., Kamaruzzaman, S. N. and Sing, G. C. (2010) 'A study on causes of accident and prevention in Malaysian construction industry', Journal of Design and Built, 3, pp. 95-113. Available at: https://umexpert.um.edu.my/file/publication/o0004806_65910.pdf\#page=102.

De Silva, N. and Wimalaratne, P. L. I. (2012) 'OSH management framework for workers at construction sites in Sri Lanka', Engineering, Construction and Architectural Management, 19(4), pp. 369-392. doi: 10.1108/09699981211237094.

Eskandari, D. et al. (2017) ‘A Qualitative Study on Organizational Factors Affecting Occupational Accidents.', Iranian journal of public health. Tehran University of Medical Sciences, 46(3), pp. 380-388. Available at:

http://www.ncbi.nlm.nih.gov/pubmed/28435824 (Accessed: 2 December 2018).

Fusch, P. I. and Ness, L. R. (2015) 'Are we there yet? data saturation in qualitative research', The Qualitative Report, 20(9), pp. 1408-1416. Available at: http://www.nova.edu/ssss/QR/QR20/9/fusch1.pdf.

Knibbs, M. (2009) Major hazards on construction sites - HSI Magazine. Available at: https://www.hsimagazine.com/pressrelease/major-hazards-on-construction-sites (Accessed: 9 December 2018).

Larson, E. L. and Liverman, C. T. (2011) Preventing Transmission of Pandemic Influenza and Other Viral Respiratory Diseases. Washington: National Academies Press. doi: 10.17226/13027.

Lombardi, D. A. et al. (2009) 'Factors influencing worker use of personal protective eyewear', Accident Analysis and Prevention, 41(4), pp. 755-762. doi: 10.1016/j.aap.2009.03.017.

Lundstrom, T. et al. (2002) 'Organizational and environmental factors that affect worker health and safety and patient outcomes', American Journal of Infection Control, 30(2), pp. 93-106. doi: 10.1067/mic.2002.119820.

Magoro, F. M. (2012) Knowledge, attitudes and practices regarding personal protective equipment. University of Limpopo. Available at: http://ulspace.ul.ac.za/bitstream/handle/10386/773/magoro_fm_2012.pdf?sequence=1\&isAllowed=y. Muema, L. M. (2017) Evaluation of personal protective equipment utilization among construction workers in Mombasa county, Kenya. Uniersity of Agriculture and Technology. Available at: http://ir.jkuat.ac.ke:8080/handle/123456789/2397. Ofori, G. (2015) 'Nature of the construction industry, its needs and its development', Journal of Construction in Developing Countries, 20(2), pp. 115-135. Available at: http://web.usm.my/jcdc/vol20_2_2015/JCDC 20(2) 2015-Art. 7(115-135).pdf. Ogundipe, K. E., Owolabi, J. D. and Olanipekun, E. A. (2018) 'Factors affecting effective use of safety wears among construction site operatives : Lessons from indigenous firms in South Western Nigeria', International Journal of Applied Engineering Research, 13(6), pp. 4314-4325. Available at:

https://www.academia.edu/36284257/Factors_Affecting_Effective_use_of_Safety_Wears_among_Construction_Site_Ope ratives_Lessons_from_Indigenous_Firms_in_South_Western_Nigeria.

Wanjiku, M. F. (2017) Factors influencing use of personal protective equipment ( Ppe'S ) by motor vehicle repair workers in Kigandaini, Thika. Available at: http://erepository.uonbi.ac.ke/bitstream/handle/11295/102695/FLACIAH WANJIKU MUNYUA FINAL PROJECT.pdf?sequence=1\&isAllowed $=\mathrm{y}$. 